\title{
Long-term domiciliary oxygen therapy in cor pulmonale complicating chronic bronchitis and emphysema
}

\author{
R. J. L E G G E T T, N.J . COOK E ${ }^{1}$, L . CLA N C Y ${ }^{2}$, \\ A. G . LEI T CH, B. J . K I R B Y ${ }^{3}$, a nd D.C. F L E NLEY \\ Department of Medicine, University of Edinburgh, The Royal Infirmary, Edinburgh EH3 $9 Y W$
}

\begin{abstract}
Leggett, R. J., Cooke, N. J., Clancy, L., Leitch, A. G., Kirby, B. J., and Flenley, D. C. (1976). Thorax, 31, 414-418. Long-term domiciliary oxygen therapy in cor pulmonale complicating chronic bronchitis and emphysema. Ten patients with cor pulmonale complicating severe chronic bronchitis and emphysema have been treated with 2 litres/min of oxygen for prolonged periods in the day, at home, over 12 to 62 months. Two patients died after 12 and 36 months of treatment. Pulmonary arterial pressure was reduced in seven patients, and red cell mass in eight, when the oxygen was given for over 15 hours in the day. Hospital inpatient treatment was greatly reduced following the start of long-term oxygen treatment in all patients. This treatment is expensive, and a controlled trial is necessary to establish its definitive place and cost-effectiveness, but the results of such a current Medical Research Council trial will not be available for a further two years.
\end{abstract}

Chronic bronchitis and emphysema complicated by hypoxic cor pulmonale carries a grave prognosis, with a cumulative mortality of $60-70 \%$ over the four years following the first episode of cardiac failure (Renzetti, McClement, and Litt, 1966; Ude and Howard, 1971). In the 'mile-high' city of Denver, Colorado, Neff and Petty (1970) halved this expected mortality in such patients who were treated with oxygen continuously over a period of 41 months. In five similar patients studied at sea level, Stark, Finnegan and Bishop (1973) showed that oxygen given for 15 hours in the day over 6 to 15 months could reduce both the frequency of congestive cardiac failure and the elevated pulmonary vascular resistance. However, Anderson et al. (1973) could find little benefit in 14 patients treated with oxygen for only 12 hours in the day over 15 to 30 months. In an attempt to define objective criteria for the use of this treatment, we have made repeated measurements of respiratory function, arterial blood gas tensions, red cell mass, cardiac output, and pulmonary vascular pressures in 10 such patients before and during treatment with oxygen given over 7 to 62 months.

Present address:

iNorthern General Hospital, Edinburgh

'Department of Respiratory Diseases, University of Edinburgh, City Hospital, Edinburgh

${ }^{3}$ Postgraduate Medical Institute, University of Exeter

\section{PATIENTS AND METHODS}

The patients ( 3 women, 7 men) were aged betwee 43 and 67 years, and all had suffered from chronio productive cough and progressive dyspnoea for at least six years. At the start of the study all had arterial hypoxaemia $\left[\mathrm{Po}_{2} 3 \cdot 3-6 \cdot 8 \mathrm{kPa}(25-51 \mathrm{mmHg})\right]$ whem breathing air, and nine also had chronic hypercapni\$ [PCO $26 \cdot 3-8 \cdot 7 \mathrm{kPa}(47-65 \mathrm{mmHg})]$. All had had one oo more previous episodes of clinical cor pulmonale as. indicated by raised jugular venous pressure an\& ankle oedema. Chronic bronchitis and emphysem was diagnosed from the history, clinical examination and chest $x$-ray (which excluded pulmonary fibrosis) and the presence of persistent airways obstruction (FEV 1.0 0.3-1.0, mean 0.56 \pm 0.21 litres). Haemato crit averaged $57.5 \%$, secondary polycythaemia being confirmed by a red cell mass of $30-87 \mathrm{ml} / \mathrm{kg}$ a measured by the ${ }^{51} \mathrm{Cr}$ method (normal range: met 26-33 ml $/ \mathrm{kg}$; women 22-29 ml/kg).

Right heart catheterization was carried out with the patient supine and when breathing air at rest on a occasions. Cardiac output was measured witff cardio-green dye dilution, with injection of dye into the main pulmonary artery, in all patients, and also except in cases 4 and 5, by the direct Fick methoo The dye dilution and Fick estimates agreed withi但 $\pm 10 \%$. Pulmonary vascular pressures were referred 
to zero as a point $5 \mathrm{~cm}$ vertically below the manubriosternal angle. Pulmonary wedge pressures were measured in all patients at the initial catheterization, but, except in cases 3 and 7, this was not technically possible at the final catheterization, which was carried out by the 'floating catheter' technique. In cases $1,2,4,5,6$, and 8 the assumed value of the wedge pressure (Table II) was based upon the mean of the value on the previous two occasions, but in cases 9 and 10 , where the pulmonary diastolic pressure had fallen to below the mean value of the previous wedge pressures, the wedge pressure was arbitrarily assumed to be one half the value of the pulmonary diastolic pressure on that occasion.

Pulmonary hypertension was present in all patients initially, the mean pulmonary arterial pressure ranging from 19 to $52 \mathrm{mmHg}$, with a cardiac index of 1.9 to $4.91 \mathrm{~min}^{-1} \mathrm{~m}^{-2}$, and pulmonary vascular resistance between 22.6 and $104.2 \mathrm{kPa} \mathrm{l}^{-1} \mathrm{~s} \mathrm{~m}^{-2}$.

Controlled oxygen therapy was provided through nasal prongs with an oxygen flow of 2 litres/min from $48 \mathrm{cu} \mathrm{ft}$ cylinders, delivered to the patients' homes twice weekly. In 7 of the 10 patients this flow of oxygen raised the arterial $\mathrm{PO}_{2}$ to over $8.0 \mathrm{kPa}$ $(60 \mathrm{mmHg})$ at the start of the treatment. Patients $1-4$ (Table I) received oxygen for 10-12 hours in the day for the first $12,16,8$, and 13 months of the study, and thereafter for 15 hours in the day throughout the study. Patients 5-10 received oxygen for 15 or more hours in the day throughout the period of treatment. All patients were in a stable clinical state, without significant change in body weight, $\mathrm{FEV}_{1.0}$, or blood gas tensions over three weeks at the time of assessment by right heart catheterization. Cor pulmonale was then controlled by digoxin and diuretics, and this treatment was continued throughout, in addition to 10-day courses of ampicillin for any exacerbation of chest infection. Patients 2, 3, 7, and 10 also received $10 \mathrm{mg}$ prednisolone per day throughout the period of observation.

The measurements were repeated after 6-16 months of treatment and again after 20-62 months of treatment, except in patient 7 , who died 12 months after starting oxygen therapy.

T A B L E I

CLINICAL AND RESPIRATORY DATA IN 10 PATIENTS BEFORE AND DURING LONG-TERM OXYGEN THERAPY

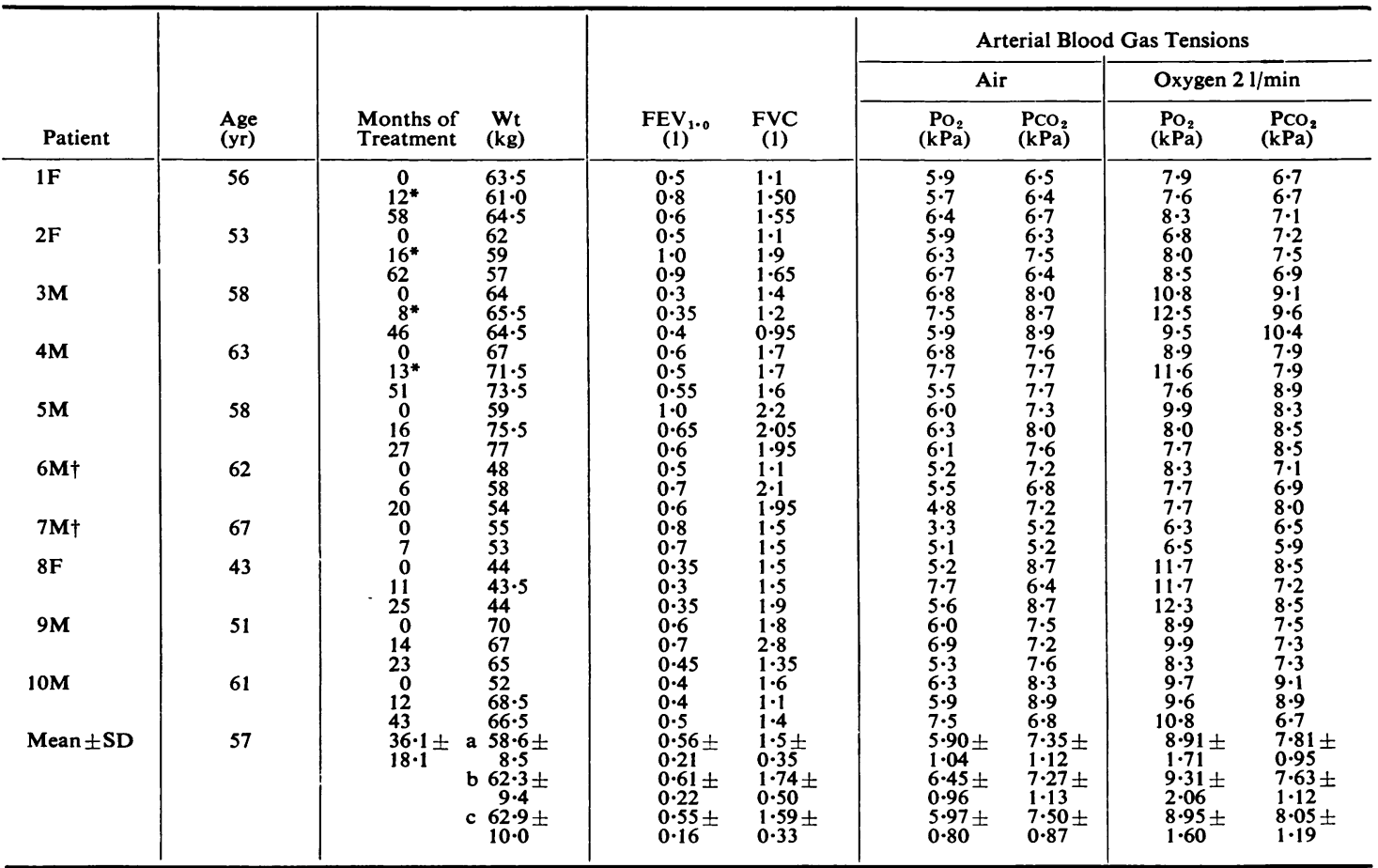

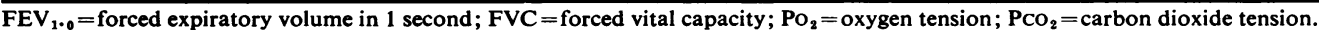
$a$, mean value before treatment; $b$, mean value at first assessment on treatment; $c$, mean value at final assessment. * Receiving oxygen for 10-12 hours/day up to this assessment; thereafter for 15 hours/day.

+Patient died. 
T A B L E I I

RED CELL MASS AND HAEMODYNAMIC MEASUREMENTS IN 10 PATIENTS BEFORE AND DURING LONG-TERM OXYGEN THERAPY

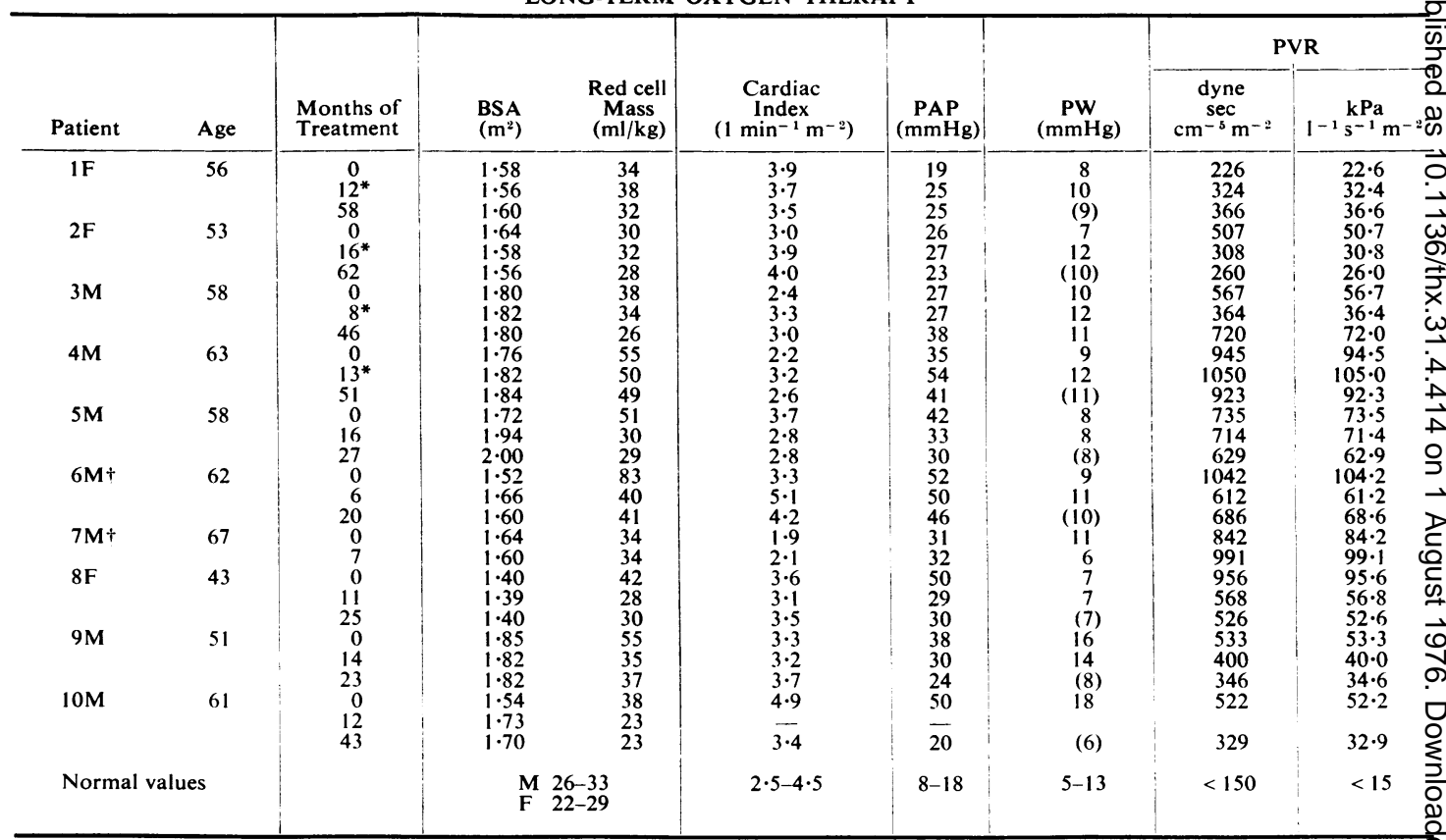

BSA = body surface area; PAP $=$ mean pulmonary arterial pressure; $P W=$ pulmonary wedge pressure (estimated values); $P V R=$ pulmonar $\$$ vascular resistance.

a, mean value before treatment; $b$, mean value at first assessment on treatment; $c$, mean value at final assessment.

Receiving oxygen for $10-12$ hours/day up to this assessment; thereafter for 15 hrs/day. $\uparrow$ Patient died.

The study was approved by the local Ethical Advisory Committee, and all patients gave informed consent to the procedures after explanation of their nature and purpose.

\section{RESULTS}

Eight of the 10 patients are alive after 23-62 months of treatment, two having died after 36 and 12 months (Tables I and II). These two patients ( 6 and 7) were the oldest (62 and 67 years) at the start of the treatment, with the most severe hypoxia when breathing air at the time [arterial $\mathrm{Po}_{2} 5 \cdot 2$ and $3.3 \mathrm{kPa}(39$ and $25 \mathrm{mmHg}$ )]. Both had greatly increased pulmonary vascular resistance $\left(104 \cdot 2\right.$ and $\left.84.2 \mathrm{kPa}^{-1} \mathrm{~s} \mathrm{~m}^{-2}\right)$. They died suddenly at home, and at necropsy both had extensive myocardial fibrosis with right ventricular hypertrophy, as well as centrilobular emphysema (case 6) and cystic bronchiectasis (case 7). All patients spent much less time in hospital after the start of oxygen therapy than in the years preceding this treatment (Fig. 1), but the treatment has made no difference to their airways obstruction (mean $\mathrm{FEV}_{1.0} 0 \cdot 56 \pm 0 \cdot 21$ litres before treatment, $0.55 \pm 0 \cdot 16$

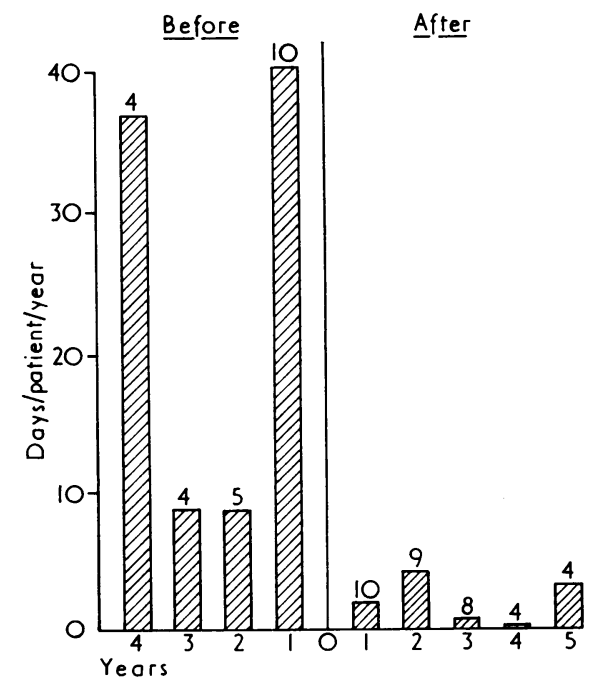

FIG. 1. Time spent in hospital with exacerbations of co pulmonale before and after the start of long-term oxygeq therapy. Numbers over the column indicate the number $\mathscr{F}$ patients observed at that time. 
litres after treatment, Table I), or to their arterial $\mathrm{Po}_{2}$ when breathing air $[5.9 \pm 1.0 \mathrm{kPa}(44 \pm 7.8 \mathrm{mmHg}$ before) $6 \cdot 0 \pm 0 \cdot 80 \mathrm{kPa}(45 \pm 6.0 \mathrm{mmHg}$ after $)]$, and has not reduced the overinflation of their lungs.

The red cell mass was reduced in eight patients while receiving oxygen for 15 hours in the day (Fig. 2). There was no change in the red cell mass of patient 7 , who remained severely hypoxic $\left[\mathrm{Po}_{2} 6.5\right.$ $\mathrm{kPa}(49 \mathrm{mmHg})]$ even when on oxygen therapy for 15 hours daily, or in patient 4 whose progress was complicated by myocardial infarction and pulmonary embolism. When receiving oxygen for only 10-12 hours in the day there were inconsistent changes in red cell mass (patients 1-4, Table II).

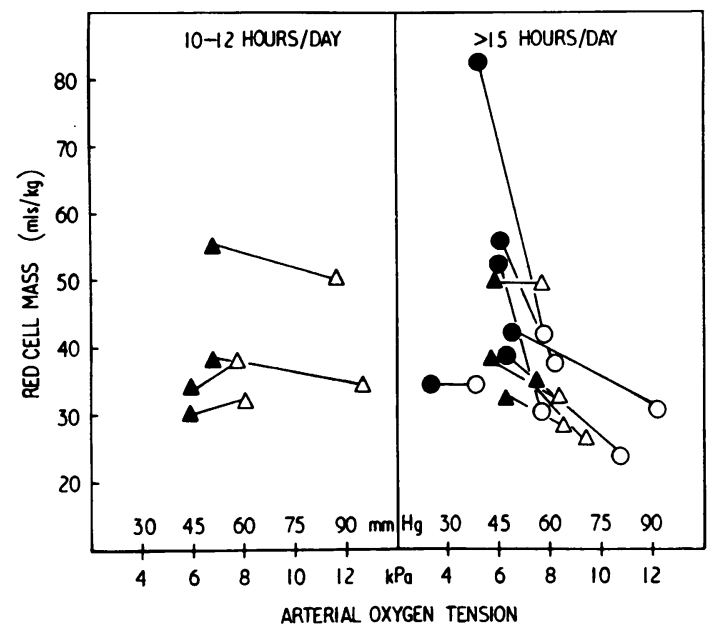

FIG. 2. Relationship between the red cell mass and arterial Po2. Left-hand panel: $\Delta$, cases 1-4 breathing air at the start: $\triangle$, when breathing $2 \mathrm{l} \mathrm{O}_{2} /$ min after 8-16 months with $\mathrm{O}_{2}$ for 10-12 hours/day. Right-hand panel: $\Delta$, cases 1-4 when breathing air at this second assessment; $\triangle$, cases $1-4$ when breathing $2 \mathrm{l} \mathrm{O} / \mathrm{min}$ after a further 38-48 months of over 15 h/day of oxygen. The right-hand panel also shows cases 6-10 when breathing air at the start (O), and at final assessment $(\bigcirc)$ when breathing $2 \mathrm{ll}_{2} / \mathrm{min}$, after 6-43 months of 15 h/day of oxygen.

The pulmonary vascular resistance fell in 7 of the 10 patients when oxygen was given for over 15 hours in the day (Fig. 3), but in patient 7 , in whom the resistance increased, oxygen raised the arterial $\mathrm{Po}_{2}$ to only $6.5 \mathrm{kPa}(49 \mathrm{mmHg})$. The pulmonary vascular resistance also fell in two of four patients receiving oxygen for only 12 hours per day, but in one of these (patient 3) the resistance increased later to above the

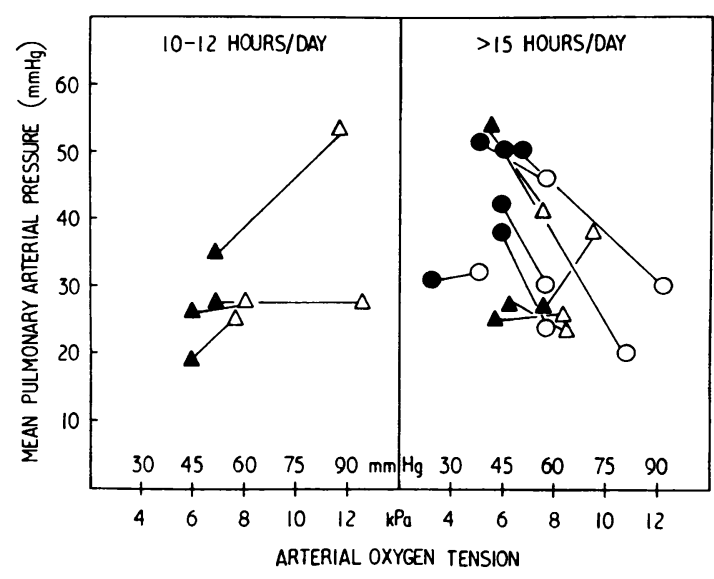

FIG. 3. Relationship between mean pulmonary arterial pressure and arterial Po2. Symbols as for Fig. 2.

pretreatment value, despite an increase in oxygen therapy to 15 hours in the day. In patient 4, pulmonary embolism was diagnosed clinically after 48 months' treatment, which may have accounted for the persistent pulmonary hypertension. We have no reason to think that any of these patients neglected to take the prescribed amount of oxygen. None of the patients has returned to work, and the eight survivors remain considerably limited in exercise tolerance despite oxygen therapy when at rest, but all are ambulant, and their cor pulmonale is easily controlled with digoxin and diuretics. The alveolar to arterial oxygen tension gradient when breathing air, which at the start of the study varied from $2 \cdot 7$ to $10.7 \mathrm{kPa}$ (20 to $80 \mathrm{mmHg}$ ), has not increased in any patient after oxygen therapy.

\section{DISCUSSION}

This uncontrolled study confirms and considerably extends the evidence that prolonged domiciliary oxygen therapy is practical (Neff and Petty, 1970; Anderson et al., 1973; Stark et al., 1973), that it can reduce the need for inpatient treatment of heart failure in patients with hypoxic cor pulmonale living at sea level, and that oxygen for over 15 hours per day can lower both a raised pulmonary vascular resistance and an elevated red cell mass (Stark et al., 1973). However, such beneficial changes seem to require that oxygen treatment raises the arterial $\mathrm{Po}_{2}$ to at least $8.0 \mathrm{kPa}(60 \mathrm{mmHg})$ probably for 15 or more hours in the day. This treatment will not improve the underlying lung condition, but we have no evidence that it produced pulmonary oxygen toxicity (Petty, 
Standford, and Neff, 1971) as the alveolar to arterial oxygen tension gradient in our patients was not increased by oxygen therapy over many months.

We have studied only patients with advanced disease, as shown by their hypoxaemia, pulmonary hypertension with previous heart failure, and secondary polycythaemia, and we suggest that the objective changes which we found implies that this treatment is of value in such patients. As the exact prognosis in the individual case with hypoxic cor pulmonale is still variable, final proof of the benefit of long-term oxygen must await the outcome of a controlled trial, and this is currently in progress under the auspices of the Medical Research Council, but the results will not be known for at least two more years. Furthermore, we cannot be certain that the reduction in inpatient treatment (Fig. 1) did not result from improved supervision of these patients at their bimonthly outpatient attendance during our trial, but we are impressed by the objective changes in pulmonary vascular resistance and red cell mass.

Long-term oxygen is expensive if given at a flow of $21 / \mathrm{min}$ for 15 or more hours in the day from $48 \mathrm{cu} \mathrm{ft}$ cylinders. Ten to 14 of these cylinders are required each week by each patient to meet their oxygen requirements. The cost can be reduced if oxygen is supplied from larger cylinders (120 or $240 \mathrm{cu} \mathrm{ft}$ ), but these are extremely heavy and require special arrangements for delivery. Alternative oxygen sources include the oxygen concentrator (Stark and Bishop, 1973) and the liquid oxygen system (Linde Division of Union Carbide) (Neff and Petty, 1970; Petty and Finigan, 1968), which also allows for patient-carried oxygen therapy, and both of these systems are currently being evaluated in Britain.

In view of this high cost and the minor inconvenience of the treatment to the patient, we do not advocate widespread use of long-term oxygen therapy at present until the outcome of controlled clinical trials is known. In particular, we deprecate either intermittent or prolonged administration o $\overrightarrow{\overline{\vec{m}}}$ oxygen as a symptomatic treatment for breathlessness in resting patients with chronic obstructive airways disease without prior demonstration that they de्ब indeed have arterial hypoxaemia when breathing ai (Block, Castle, and Keitt, 1974).

\section{REFERENCES}

Anderson, P. B., Cayton, R. M., Holt, P. J., and Howar $\overrightarrow{\overrightarrow{2}}$ P. (1973). Long-term oxygen therapy in cor puj monale. Quarterly Journal of Medicine, 42, 563.

Block, A. J., Castle, J. R., and Keitt, A. S. (1974). Chroni oxygen therapy: treatment of chronic obstructive pulmonary disease at sea level. Chest, 65, 279.

Neff, T. A. and Petty, T. L. (1970). Long-term continuous. oxygen therapy in chronic airway obstructione mortality in relationship to cor pulmonale, hypoxi and hypercapnia. Annals of Internal Medicine, 72, 621.

Petty, T. L. and Finigan, M. M. (1968). Clinical evaluatiog of prolonged ambulatory oxygen therapy in chronic airway obstruction. American Journal of Medicine 45, 242.

—-, Standford, R. E., and Neff, T. A. (1971). Continuous oxygen therapy in chronic airway obstruction. Annals of Internal Medicine, 75, 361.

Renzetti, A. D., Jr., McClement, J. H., and Litt, B. D (1966). The Veterans Administration Co-operatives Study of Pulmonary Function. III. Mortality i relation to respiratory function in chronic obstructive pulmonary disease. American Journal of Medicine, 41, 115.

Stark, R. D. and Bishop, J. M. (1973). New method fo oxygen therapy in the home using an oxygen cont centrator. British Medical Journal, 2, 105.

__, Finnegan, P., and Bishop, J. M. (1973). Long-term domiciliary oxygen in chronic bronchitis wit pulmonary hypertension. British Medical Journats 3, 467.

Ude, A. C. and Howard, P. (1971). Controlled oxyge therapy and pulmonary heart failure. Thorax, 26, 572.

Requests for reprints to: Dr. D. C. Flenley, Departmen of Medicine, Royal Infirmary, Edinburgh, EH3 9YW. 